Instrument Number DE-FG01-91CE15497

United States Department of Energy

Quarterly Report

Period 9-16-92 through 12-15-92

Submitted by

Nu-Bore Systems

Wichita Falls, Texas

Mr. Charles Koster

\title{
DESIGN, BUILD, DEVELOP AND TEST A FIELDWORTHY SPIRAL TOOL AND PACKER FOR CASING REPAIR
}

\section{DISCLAIMER}

This report was prepared as an account of work sponsored by an agency of the United States Government. Neither the United States Government nor any agency thereof, nor any of their employees, makes any warranty, express or implied, or assumes any legal liability or responsibility for the accuracy, completeness, or usefuiness of any information, apparatus, product, or process disclosed, or represents that its use would not infringe privately owned rights. Reference herein to any specific commercial product, process, or service by trade name, trademark, manufacturer, or otherwise does not necessarily constitute or imply its endorsement, recommendation, or favoring by the United States Government or any agency thereof. The views and opinions of authors expressed herein do not necessarily state or reflect those of the United States Government or any agency thercof. 


\section{Design, Build, Develop, and Test A Fieldworthy Spiral \\ Tool and Packer for Casing Repair}

\subsection{Introduction}

The oil and gas industry has an opportunity for protecting the environment and conserving resources by sealing wellbore leakage in damaged wells. This leakage has various causes, such as corrosion damage, cracked or otherwise defective casing, and unwanted perforations. The opportunity comes in the form of a newly designed and partially developed method for internally sealing well casing or tubing to prevent leakage. Once this method is fully developed, our country can realize significant financial savings in addition to the environmental protection and resource conservation benefits.

A new method for sealing casing is currently under development by Nu-Bore Systems. The method involves internally lining a section of the wellbore with a multi-layer spiral wrapping of a high strength, corrosion resistant metal interleaved with a high bond strength, resilient epoxy. The high strength metal is preferably a copper based alloy hardened to a very high strength in order to resist the internal and external pressures of downhole environments. The epoxy adhesive formulation is one that forms a bond between the steel inner wall of the casing and copper alloy strip. The copper alloy strip spiral wraps are interleaved with epoxy, and the whole system provides a high level of outward directed spring force and, thus, resists both internal and externally directed forces. This method has been assessed by the Department of Energy, and the magnitude of the oilfield need and the technology are described in a DoE report entitled, "Downhole Casing Repair System" (OERI Number 013152). In this report, the cost savings to the nation's energy program was estimated to be in the range of hundreds of millions of dollars per year, and the method was judged technically feasible once certain well defined engineering obstacles are overcome.

\subsection{Background of the Program}

The spiral lining method reduces cost because of its modular tooling and simple process. It increases reliability by using materials resistant to corrosive conditions, and it makes it much simpler to get equipment to remote wellsite locations. The Nu-Bore method needs further development, however, to take it from its current stage in which it is limited to relatively short lining lengths, to a stage closer to commercial operation in which it will be capable of very long lengths.

The current program involves development of a segmented connecting joint for an inflatable rubber packer. Packers are tubular components with a relatively thick wall and are made from vulcanized rubber reinforced with cord much like vehicular 
tires. They are used in several steps of the spiral sealing method, mainly for firmly anchoring the ends of the downhole tools during installation and for applying outward pressure at the lining/casing interface during the cure cycle for the epoxy adhesive.

In theory, the spiral lining process has no length limitation. In practice however, as the length of lining increases, the length of the pressure cure packer must be increased to match the finished length of the lining itself. The packer currently used in the $\mathbf{~ N u}$-Bore method is approximately 40 feet long. This becomes the limiting length of the spiral wrapped lining.

For a lining that is several hundred feet long, a long coiled rubber packer would be required. This would be somewhat difficult to transport and deploy, and extremely difficult to manufacture. If long packers could be built up from smaller segments, manufacture would be simpler and less expensive, and packers would be far easier to transport and to work with in the field. Another consideration is the fact that if a long packer is damaged, begins to leak, or becomes distorted, the entire unit is prohably unusable. With a segmented packer, only those lengths affected would need replacement.

The objective of this program, therefore, is to develop a joint between packer segments that is easily assembled before lowering downhole and easily disassembled after the sealing job is done. In addition, this tool joint must expand uniformly as though it were a part of the rubber and must not fail under the relatively high pressure of the epoxy cure cycle.

The overall goal of the work is to design, build, develop, and test a spiral tool and packer into a single universal tool that can repair casings with diameters varying from 4.5 to 7 inches.

Task 1. Define, analyze, and complete the engineering requirements for the subject tool system.

Task 2. Perform the engineering design.

Task 3. Complete the engineering drawings for the tool system, including both the overall layout and the individual components.

Task 4. Complete a materials list, and purchase the materials.

Task 5. Establish test parameters for the tool system.

Task 6. Build a prototype. 
Task 7. Perform tests to validate performance of the individual components and the overall assembly.

Task 8. Prepare final report for DOE.

\subsection{Engineering Program Plan}

The action plan of this program is divided into the following areas:

- Define and analyze engineering requirements for the system.

- Produce layout drawings of the tooling design.

- Select special manufacturing treatments for key components.

- Establish test parameters.

- Build engineering model of the segmented packer joint.

- Perform testing to validate performance of components and overall assembly.

These tasks can be further broken down as follows:

\section{A. Engineering:}

Establish design parameters

Detail joint test model

Redesign and Test as required

Design and Detail Full Size Unit

Design Required Tooling (vulcanizing molds, etc.)

Test, redesign, and retest as required

Document for ultimate production

\section{B. Manufacturing:}

Fabricate Test Models (metal components)

Fabricate mold model

Lay up molded test model

Fabricate prototype mold

Lay up molded prototype

Fabricate test equipment as required 


\section{Test:}

Test models

Test prototype

\subsection{Program Status}

\subsection{Engineering}

- Design modifications to the end fitting components were completed. These include a profile change of the end of the packer housing, a strengthening of the beryllium copper reinforcing liner, and a redesign of the ferrule. Specification modification has been made to reflect an increase in working pressure from $1000 \mathrm{psi}$ max. to $1500 \mathrm{psi} \max$ and an ultimate test strength from 1500 psi max to $2000 \mathrm{psi}$ max. These changes are the result of current modifications and tests.

\subsection{Manufacturing}

- All parts of the initial prototype joint were received from outside vendors. Parts were inspected and accepted. As noted under engineering, the metal parts were modified as required for successful pressure testing. In all, seventeen test samples were fabricated.

\subsection{Testing}

- Third quarter testing was concentrated on end fitting design and testing. Second quarter testing had shown end fitting failures at pressures of $150 \mathrm{psi}$ to 800 psi.

- Modifications to the end fitting were made. Additional testing including this modification along with higher durometer (harder) rubber showed much higher pressure capacities of test samples.

- As internal test pressures increased, the metal reinforcing liner began to take a permanent deformation (set). Additional testing with thicker and higher tensile strength beryllium copper allowed increases in test pressures.

- As much higher test pressures (2000 psi) were achieved, a higher strength end ferrule became necessary. Although other methods were tried, the most effective was by increasing the metal thickness. 
- The spiral winding apparatus has been performing satisfactorily in repeated testing.

\subsection{Future Work}

\subsection{Engineering}

Consistent test pressures of 2000 psi (limit of the test fixture) have been achieved. Final part and assembly drawings of the end fitting will now be made.

Upgrading of the project specification is in progress.

All final documentation will be completed.

Possible patent action will be considered pending interest by the sponsor.

\subsection{Manufacturing}

New samples of the tool joint will be prepared and tested.

An intermediate segment piece is currently being manufactured and when tested, we expect that this will conclude component development. 

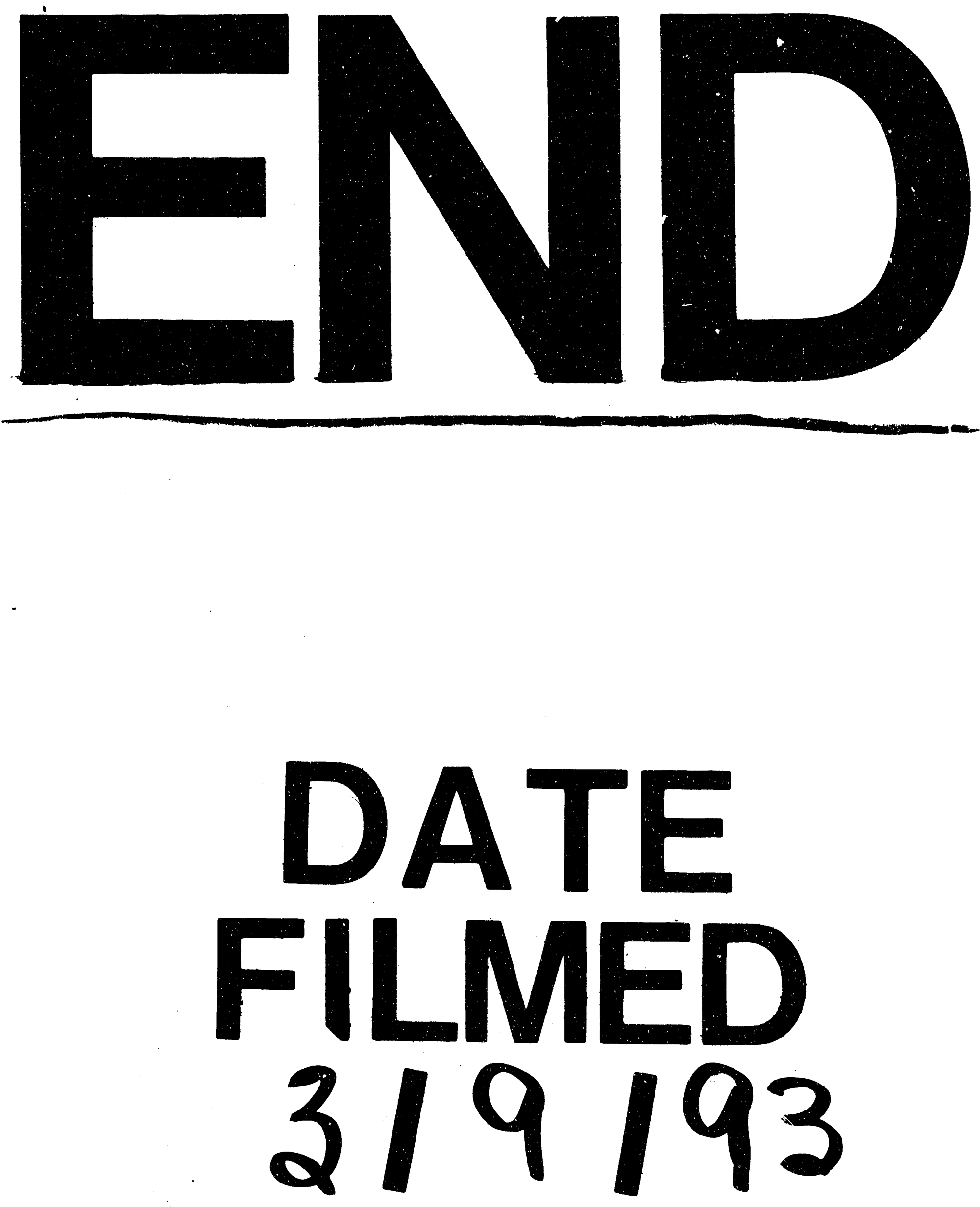
